\title{
Language Comprehension in Monolingual and Bilingual Children
}

\author{
Krista Byers-Heinlein \& Casey Lew-Williams
}

Byers-Heinlein, K., \& Lew-Williams, C. (2018). Language comprehension in monolingual and bilingual children. In E. M. Fernández \& H. Smith Cairns [Eds.]. Wiley Handbook of Psycholinguistics. 516-535. 


\begin{abstract}
Infants and toddlers grow up in a variety of language environments - for example, some environments are monolingual and some are bilingual - but nearly all children develop the ability to understand the language(s) around them. In this chapter, we trace children's path to language comprehension, from listening in infancy, to phonetic perception, speech segmentation, word learning, vocabulary development, and finally understanding language in real time. For both monolinguals and bilinguals, developing fluency in language comprehension in infancy and toddlerhood sets the stage for later language and school success.
\end{abstract}

Keywords: Children; infants; toddlers; language comprehension; language acquisition, bilingualism; phonetic perception; speech segmentation; word learning; vocabulary 


\section{Introduction}

Long before they speak their first words, children begin to understand the language that they hear around them. Indeed, language comprehension - extracting meaning from speech - outpaces language production throughout development (Fenson et al., 2007). Nevertheless, understanding speech is a challenging and multi-faceted task. At minimum, children must identify and perceive speech sounds, parse the speech stream into its constituent words, identify the meaning of these words, consider their order in the context of a language's grammar, and link the entire message to the speakers' intended meaning (see Figure 1). All of this happens quickly and in real time: even "slow" infant-directed speech occurs at a rate of several syllables per second (Fernald \& Simon, 1984). When and how do children come to understand what is spoken to them?

Recent research has shown that infants extract meaning from speech much earlier than previously thought. By age 6-9 months, infants understand the meanings of many common words like feet, juice, and spoon (Bergelson \& Swingley, 2012; Tincoff \& Jusczyk, 2011). However, the path to language comprehension neither begins nor ends there. Throughout development, successful language comprehension intertwines with developing linguistic, cognitive, and social abilities.

The development of language comprehension depends on the specific nature of children's language environments. Monolingual children hear one of the world's many languages, bidialectal children hear two varieties of the same language, and bilingual and multilingual children hear two or more languages. Diversity in language experiences can take many other forms as well. Children growing up in poverty often have fewer opportunities to hear words and sentences relative to children growing up with more resources (Hart \& Risley, 1995; Weisleder \& Fernald, 2013). Some children are exposed to signed rather than to spoken languages. Children with cochlear implants hear speech that is degraded relative to children with acoustic hearing (see Pisoni, this volume; Grieco- 
Calub, Saffran, \& Litovsky, 2009; And relative to typically developing children, children with developmental language disorders experience a complex interaction between cognition and language input (Rice, Warren, \& Betz, 2005). All children must adapt to the specific challenges presented by their environments. Children whose experience reduces the quantity and quality of language exposure are often slower in language acquisition. Other children, such as bilinguals or sign language learners, develop language differently but are not delayed (see Kegl, this volume); Peña, Gillam, Bedore, \& Bohman, 2011; Petitto et al., 2001; Werker \& Byers-Heinlein, 2008).

In this chapter, we focus on cross-linguistic research with monolingual and bilingual infants and toddlers to explore how they navigate the path from hearing to understanding. While most research to date has investigated monolingual children, there is growing interest in understanding language acquisition in the many children around the world who encounter multiple languages early in life. Note that while we use the blanket term "bilingual" to refer to children acquiring two or more languages, this is anything but a one-size-fits-all category. There are vast differences in the quality and quantity of language experiences across different households and populations, the timing of exposure to different languages, as well as many other demographic, cultural, and linguistic differences (McCabe et al., 2013). Considering both monolingual and bilingual learners enriches what we know about language learning in general.

Each section of the chapter begins with an overview of research on monolingual children and then discusses relevant findings from research on bilingual children. We start by describing how infants' looking and listening facilitate their entry into language, and we then discuss phonetic development, speech segmentation, word learning, and real-time language processing. We conclude with a section on how monolingual and bilingual infants learn from the imperfect speech that is inherent in the complexities of natural language environments. 


\section{Looking and listening}

Language acquisition begins with looking at and listening to native speakers of the ambient language(s). From very early in life, infants attend to speech over other types of sounds

(Vouloumanos \& Werker, 2007), and quickly target their attention to the native language or languages (Byers-Heinlein, Burns, \& Werker, 2010; Moon, Cooper, \& Fifer, 1993). Infants' preference for language is not limited to the spoken modality: 6-month-old hearing infants with no exposure to sign language look more at linguistic signs than non-linguistic gestures (Krentz \& Corina, 2008). Young infants may also be sensitive to the notion that language can convey information between speakers. For example, 12-month-olds understand that speech, but not other types of vocalizations such as coughing, can communicate information to a listener (Martin, Onishi, \& Vouloumanos, 2012).

For infants growing up bilingual or multilingual, it is not enough to simply attend to their languages in an undifferentiated fashion. Instead, they must acquire each as an independent communicative system, which hinges on an ability to detect the differences between languages (Byers-Heinlein, 2014b). While fully disentangling their two languages might be a somewhat gradual process (Byers-Heinlein, 2014b), there is evidence that the ability to differentiate two languages emerges early in life. At birth, monolingual and bilingual infants can discriminate between languages that differ in rhythm, such as English and French (Byers-Heinlein, Burns, \& Werker, 2010; Mehler et al., 1988; Nazzi, Bertoncini, \& Mehler, 1998). By age 4-5 months, monolinguals and bilinguals can also discriminate between rhythmically similar languages that belong to the same category as their own native language (Bosch \& Sebastián-Gallés, 2001; Molnar, Gervain, \& Carreiras, 2014; Nazzi, Jusczyk, \& Johnson, 2000). Infants can also distinguish languages using visual cues available on the lips and face of their interlocutors. Both English-monolingual and French-English bilingual 4- and 6-month-old infants can tell apart visual English and French when they see talking faces with the sound turned off. 
However, only bilingual infants retain this sensitivity at 8 months (Weikum et al., 2007). Eight-monthold bilinguals also show enhanced abilities to visually discriminate unfamiliar languages (SebastiánGallés, Albareda-Castellot, Weikum, \& Werker, 2012). Such sensitivities could help bilinguals extract meaning in their complex linguistic environments. Thus, infants use a range of auditory and visual cues to break into multiple languages, laying the foundation for discovering the sounds and sequences of sounds that comprise each language.

\section{Phonetic development}

Words are built from sounds, and languages vary in terms of which sound differences are meaningful. These meaningful differences group speech sounds into phonetic categories. For example, the phonetic difference between $/ \mathrm{r} /$ and $/ \mathrm{I} /$ is meaningful in English, as in the words "rake" and "lake". This difference is not meaningful in Japanese, and so Japanese speakers tend to ignore it and group / $\mathrm{r} /$ and /I/ into the same phonetic category. Infants cannot know at birth whether they will be growing up in an English, Japanese, or bilingual English-Japanese environment. As such, newborn infants are sensitive to most sound differences that are meaningful across the worlds' languages. Important development occurs within the first year of life, when monolinguals lose sensitivity to nonnative sound distinctions (Werker \& Tees, 1984), but gain sensitivity to native language distinctions (Kuhl et al., 2007). This developmental pattern is often referred to as perceptual narrowing, and is thought to be driven in part by infants' innate sensitivity to distributional regularities available in the input (Maye, Werker, \& Gerken, 2002; Thiessen \& Pavlik, 2013). Developing phonetic categories, together with growing knowledge of native language words, help children interpret whether a speech sound difference is meaningful or not (Dietrich, Swingley, \& Werker, 2007).

Evidence from bilingual infants suggests that early language experience can affect phonetic development in unexpected ways (Byers-Heinlein \& Fennell, 2014). For example, Spanish-Catalan 
bilingual infants show a U-shaped developmental pattern for their perception of vowels that exist only in Catalan (/e/ - / $\varepsilon /)$ : they readily discriminate this phonetic difference at 4- and 12-months of age, but sometimes fail to do so at 8 months of age (Bosch \& Sebastián-Gallés, 2003). Monolingual Catalan-learning infants discriminate the same phonetic difference throughout the first year of life. While there are numerous different explanations for this finding (Byers-Heinlein \& Fennell, 2014), one explanation focuses on how Spanish and Catalan link sound to meaning. Spanish and Catalan are both Romance languages with many cognates, which have similar meanings and differ on only a few sounds which are often vowels (for example Catalan pilota and Spanish pelota, both meaning ball). Bilinguals acquiring these close languages may learn to ignore some vowel variability, and to focus on the invariant consonants (Sebastián-Gallés \& Bosch, 2009). Studies with populations of bilinguals learning languages that are not closely related, such as French-English and Spanish-English bilinguals, have found patterns of phonetic development that are similar to those of monolinguals (Burns, Yoshida, Hill, \& Werker, 2007; Sundara \& Scutellaro, 2010; Sundara, Polka, \& Molnar, 2008). More research with bilinguals is needed to investigate a wider variety of phonetic contrasts and language pairs.

Mature language-specific phonetic categories can help infants interpret meaning in speech, but there is also evidence that consistent links between sound and meaning can actually help infants interpret speech sounds. In laboratory studies, infants who hear two sounds consistently paired with two different objects are more likely to discriminate these sounds than infants who hear the sounds paired randomly with the objects (Yeung \& Werker, 2009; Yeung, Chen, \& Werker, 2013).

\section{Finding words in the speech stream}

While infants are learning about the sounds of their native language(s), they also begin learning which sounds go together to form words (see Levine, Strother-Garcia, Hirsh-Pasek, \& Michnick 
Golinkoff, this volume). Spaces signal word boundaries in written language, but silent pauses are not reliable cues to word boundaries in spoken language as they often occur in the middle of words. Children do sometimes hear words in isolation or at the edge of an utterance, and these words are relatively easy for them to pick out of the speech stream (Brent \& Siskind, 2001; Johnson, Seidl, \& Tyler, 2014; Lew-Williams, Pelucchi, \& Saffran, 2011; Shukla, Nespor, \& Mehler, 2007). However, most words occur in the middle of utterances, and infants must locate these words in order to eventually learn word meanings and interpret word combinations.

Infants can recognize familiar sound combinations in running speech - word forms - during the middle of their first year (Bortfeld, Morgan, Golinkoff, \& Rathbun, 2005). In a typical study, infants hear a list of familiar words, and later hear passages that either do or do not contain those words. Infants prefer listening to passages with the familiar list of words (Houston \& Jusczyk, 2003), and are not fooled by similar-sounding words (Jusczyk \& Aslin, 1995). This demonstrates their ability to segment the speech stream. Infants are especially skilled at segmenting words from familiar talkers and languages, particularly when words adhere to patterns typical of the native language (Brent \& Cartwright, 1996; Houston \& Jusczyk, 2000; Jusczyk, Houston, \& Newsome, 1999; Polka \& Sundara, 2012). Bilingual infants can flexibly and efficiently recognize word forms in each of their two native languages (Polka \& Sundara, 2003; Vihman, Thierry, Lum, Keren-Portnoy, \& Martin, 2007).

How do infants locate word forms in the speech stream? A learning mechanism known as statistical learning allows infants to track sounds and syllables that occur together with the most consistency (see Romberg \& Saffran, 2010). The central idea is as follows: sounds that occur together often in a language (such as b-a-b-y in English) are likely to be words, and sounds that rarely occur together (b-a-g-u) are less likely to be words. After even brief opportunities to learn, 8-month-olds can detect words hidden in artificially constructed languages (Aslin, Saffran, \& Newport, 1998; 
Saffran, Aslin, \& Newport, 1996) and in carefully controlled passages of natural but unfamiliar languages (Lew-Williams et al., 2011; Pelucchi, Hay, \& Saffran, 2009). Some sources of variation, such as varying word lengths, can make statistical learning more difficult (Johnson \& Tyler, 2010).

Over time statistical learning begins to interact with children's growing native language experience (Graf Estes \& Bowen, 2013; Lew-Williams \& Saffran, 2012). For example, infants sometimes use language-specific cues (e.g., in English, paying attention to the stressed syllables that often occur at the beginning of words) rather than statistical cues when segmenting speech (Johnson \& Jusczyk, 2001; Johnson \& Seidl, 2009; Thiessen \& Saffran, 2003). Moreover, there is a coupling between language input and the dynamic nature of caregiver-child interaction: tactile cues from adults (Seidl, Tincoff, Baker, \& Cristià, 2014), and highly familiar word forms such as the child's own name also aid in segmenting the speech stream (Bortfeld et al., 2005; Mersad \& Nazzi, 2012). To date, most research on speech segmentation has studied monolingual infants, and future research will need to investigate the complexities of segmentation in bilingual contexts.

\section{Word learning}

Once children locate a word in the speech stream, how do they figure out its intended meaning? Despite the potential difficulty of this task, children are powerful word learners, deploying a myriad of cognitive, linguistic, and social resources (Hollich, Hirsh-Pasek, \& Golinkoff, 2000). As they gradually gain familiarity with common sequences of sounds, they begin to link those sequences to meaning (Graf Estes, Evans, Alibali, \& Saffran, 2007). Children can sometimes infer the basic meaning of a word from a single example, a process called fast mapping (Carey \& Bartlett, 1978). These processes set the stage for more protracted learning of a word's full meaning (Horst \& Samuelson, 2008; Swingley, 2010). The rest of this section will discuss some of the many contributors to successful word learning, as well as the ultimate outcome of this learning: a child's vocabulary. 


\section{Associative learning mechanisms}

The ability to form associations between words and their referents is foundational to mature word learning. One-year-olds can successfully associate a picture of an object with a repeated word (Mackenzie, Curtin, \& Graham, 2012b; 2012a; Werker, Cohen, Lloyd, Casasola, \& Stager, 1998). Even 6-month-olds can do so if given appropriate prosodic information (Shukla, White, \& Aslin, 2011). Associative word learning abilities are robust regardless of whether children are growing up monolingual or bilingual (Byers-Heinlein, Fennell, \& Werker, 2012). Young infants can also associate words and objects in more challenging conditions. Even when the same word is paired with several pictures, or when the same picture is paired with several words, infants are able to track which words and pictures co-occur most reliably (Smith \& Yu, 2008; Vouloumanos \& Werker, 2009).

A number of different perceptual and attentional cues can support the formation of these word-object links. For example, English-learners tend to learn concrete words such as nouns before other types of words (Bergelson \& Swingley, 2013; Gentner, 1982), suggesting that some types of words are easier to learn than others. Low-level information can also affect how easily infants learn a new word. Infants are better at forming associations if an object is labeled synchronously with its motion (Gogate \& Bahrick, 2001; Matatyaho-Bullaro, Gogate, Mason, Cadavid, \& Abdel-Mottaleb, 2014), or if the labeled object is dominant in the infant's field of view (Yu \& Smith, 2012).

\section{Word learning biases}

Children do not associate words with just any meaning, Instead, they expect new words to refer to whole objects, rather than to their parts, and expect newly learned words to refer to categories of objects of the same shape or kind (see Hollich, Golinkoff, \& Hirsh-Pasek, 2007;

Markman, 1991). The origin of such expectations continues to be an important area of inquiry. Researchers have proposed diverse explanations: that these biases are built into the word-learning 
system (Markman, 1991), that they arise from children's social understanding (Bloom \& Markson, 1998), or that they are learned from regularities in the environment (Smith, Jones, Landau, Gershkoff-

Stowe, \& Samuelson, 2002). Regardless of their origin, evidence from bilingual and multilingual infants suggests that early word learning environments can change infants' use of these biases. Using a word learning bias known as mutual exclusivity, children reject two labels for the same object, expecting each object to have only one basic-level label (Markman \& Wachtel, 1988). This has been demonstrated in monolinguals as young as 16-18 months (Halberda, 2003; Markman, Wasow, \& Hansen, 2003). However, children growing up in bilingual and multilingual environments do not show mutual exclusivity from the same age (Byers-Heinlein \& Werker, 2009; 2013; Houston-Price, Caloghiris, \& Raviglione, 2010). This difference is likely because bilingual and multilingual children, unlike monolinguals, hear multiple labels for the same object - one in each language. Thus, while monolinguals' experience supports the notion of one-to-one mappings between words and objects, bilinguals' experience could lead to more flexible word learning.

\section{Social information}

Infants also exploit rich social cues available in the environment, such as pointing and eye gaze, to help determine a word's meaning (Hollich et al., 2000). For example, 18-month-old infants are more likely to link a speaker's utterance with an object when the speaker is attending to that object (Baldwin et al., 1996). Similarly, when several different objects are present, children use their interlocutor's eye gaze and pointing to figure out what she is referring to (Baldwin \& Moses, 2001). Beyond simply providing cues to a word's meaning, infants' understanding of a speaker's referential intentions is foundational to learning new words (Frank, Goodman, \& Tenenbaum, 2009; Waxman \& Gelman, 2009). 
There is also evidence that infants' language background can affect their sensitivity to different types of social information. For example, because different speakers use different languages, bilingual children might be particularly sensitive to communicative information provided by a speaker.

Consistent with this possibility, 3-year-old bilinguals are better than monolinguals in using a speaker's gaze to find where a toy is hidden (Yow \& Markman, 2011).

\section{Vocabulary}

Children's vocabulary size provides a key index of their language development. To measure their receptive vocabulary - the words they can understand - children as young as $21 / 2$ years are typically asked to point at which picture corresponds to a particular word (Dunn \& Dunn, 2007). For younger children, parents check off different words that their child understands from a predetermined list (Fenson et al., 2007). In both cases, the number of words understood is compared to age-referenced norms to understand how a particular child compares to her peers. Studies that extrapolate from such measures suggest that the average monolingual 12-month-old can understand about 100 words, which jumps to around 550 words for the average monolingual 18-month-old (Mayor \& Plunkett, 2011).

Children's receptive vocabulary is almost invariably larger than their productive vocabulary, as typically they understand all the words they can say, but do not say all the words they can understand. This appears to be especially true for bilingual children, who may have particularly disproportionate receptive vocabularies compared to their productive vocabularies (Gibson, Oller, Jarmulowicz, \& Ethington, 2011).

Typically, bilingual children understand fewer words in either of their languages than monolingual children understand in their single language (Bialystok, Luk, Peets, \& Yang, 2010; PoulinDubois, Bialystok, Blaye, Polonia, \& Yott, 2012). This is thought to arise because bilingual children's 
language input is inherently split between two languages (Byers-Heinlein \& Lew-Williams, 2014). Despite knowing fewer words in each language, bilingual children usually learn words at the same rate as monolinguals, and importantly, they understand a similar number of total words when both languages are considered (De Houwer, Bornstein, \& Putnick, 2013; Marchman, Fernald, \& Hurtado, 2010; Pearson, Fernández, \& Oller, 1995; Thordardottir, 2011). Bilingual children also understand translation equivalents - cross-language synonyms like English cat and Spanish gato - from an early age (De Houwer, Bornstein, \& De Coster, 2006; Pearson et al., 1995; Umbel, Pearson, Fernández, \& Oller, 1992).

While there can be imbalances in vocabulary across a bilingual's two languages, there is no consistent evidence that bilingual children are more likely than monolingual children to experience delays or deficiencies in language learning. Bilingualism is not considered a risk factor for language learning, and bilingualism does not impose an additional burden on children diagnosed with impairments such as specific language impairment and autism spectrum disorders (Paradis, Crago, Genesee, \& Rice, 2003; Peterson, Marinova-Todd, \& Mirende, 2012).

\section{Understanding language in real time}

Listeners usually encounter the words they know, as well as those they have yet to learn, in the context of running speech. Imagine if it took minutes or hours to determine the meaning of each incoming sentence - conversation would be impossible. Instead, communication occurs in real time, and young children show a developing ability to process speech as it unfolds. Fernald and colleagues (1998) presented young children with simple sentences ("Where's the baby?"), and found that 15month-olds take approximately one second to move their eyes toward a picture of a baby, while 24month-olds do so considerably faster. Similar developmental gains in real-time processing have been observed in Spanish-learning children from low-income households (Hurtado, Marchman, \& Fernald, 
2007). These findings are also echoed in studies of children's neural responses to familiar words (Friedrich \& Friederici, 2005; Mills, Plunkett, Prat, \& Schafer, 2005). Young children even begin to recognize words after hearing partial phonetic information, such as the onset ba- of baby (Swingley, Pinto, \& Fernald, 1999).

Counter-intuitively, words in sentences can be easier for children to understand than words in isolation (Fernald \& Hurtado, 2006). One reason is that children can leverage information across different parts of an utterance. For example, Spanish-learning children can use gender-marked articles like la and el ('the') to predict whether a speaker will name an object with a masculine or feminine grammatical gender (Lew-Williams \& Fernald, 2007). Other studies show how young children exploit color and size adjectives (Fernald, Thorpe, \& Marchman, 2010). Young monolingual children can even use familiar verbs and visual scenes to learn novel nouns (Ferguson, Graf, \& Waxman, 2014; Waxman, Lidz, Braun, \& Lavin, 2009), and use sentence structure to learn the meanings of novel verbs (Naigles, 1990).

Experimental studies with young children are beginning to elucidate how these words are organized in the developing mind. Priming studies investigate whether hearing one word (e.g., "cat") helps children access words that are related in meaning ("dog") or sound ("mat"). Research shows that from around their second birthday, both monolingual and bilingual children indeed make links between words with related meanings (Arias-Trejo \& Plunkett, 2009; Singh, 2013) or with overlap in their sounds (Holzen \& Mani, 2012; Mani, Durrant, \& Floccia, 2012).

Children's ability to process language in real-time matters for later development. Children who respond faster to familiar words at age 2 have better language and cognitive outcomes in $3^{\text {rd }}$ grade, even when matched on overall vocabulary size (Marchman \& Fernald, 2008). Similar longitudinal patterns have been observed in children with autism spectrum disorders (Venker, Eernisse, Saffran, \& 
Weismer, 2013). Moreover, the speed of children's processing predicts which 18-month-old "late talkers" will make gains in language learning over the subsequent year (Fernald \& Marchman, 2012).

Children's developing language expertise is built on a foundation of exposure to high-quality, high-quantity child-directed speech (Hart \& Risley, 1995; Huttenlocher, Haight, Bryk, Seltzer, \& Lyons, 1991). On average, children from high-income families hear 3-4 times as much language as children from families on welfare. Even within low-income families, there is striking variability in the use of language in the household. Latino children from low-income families who hear more child-directed speech at home are faster in real-time language processing, and less likely to fall behind in language learning (Weisleder \& Fernald, 2013). For bilingual children, relative exposure to each language shapes language processing and word learning in each language (Hurtado, Grueter, Marchman, \& Fernald, 2014). Proficiency in one language does not carry over to the other language, as vocabulary size in one language is not related to the other, and processing efficiency in one language is not related to the other (Marchman et al., 2010).

\section{Challenges to language comprehension}

While most research has tested infants' and toddlers' understanding of clearly articulated speech, real listening conditions are far from perfect. Everyday speech is replete with mispronunciations, accents, disfluencies, and background noise. Children have more difficulty understanding degraded speech than normal speech, but their ability to cope improves with age and vocabulary size (Zangl, Klarman, Thal, Fernald, \& Bates, 2005).

Children's processing of mispronunciations provides a particularly interesting window into how they handle challenges to language comprehension. In typical laboratory studies of mispronunciations, children are shown pairs of object on a screen (e.g., a dog and a baby), and then hear a label either correctly pronounced ("Look at the baby!"), or mispronounced ("Look at the 
vaby!"). As early as age 12 months, monolinguals detect the mispronunciation, by looking less often and/or more slowly at the labeled object (Bailey \& Plunkett, 2002; Swingley, 2005; White \& Morgan, 2008). However, they still successfully identify the target object, demonstrating considerable flexibility in language comprehension. Experience improves children's word recognition: infants notice small sound changes more easily in familiar words than in newly-learned words (Fennell, 2011; Stager \& Werker, 1997).

Interestingly, there is evidence that Spanish-Catalan bilingual infants show a different pattern of processing mispronunciations than monolingual infants. As discussed previously, Spanish and Catalan share a high proportion of cognate words, such that they could be considered variant pronunciations rather than mispronunciations. Bilingual toddlers do not respond differently to correctly pronounced versus mispronounced cognates (Ramon-Casas, Swingley, Sebastián-Gallés, \& Bosch, 2009), likely because they have learned to ignore small sound variations in cognates, which do not change a word's meaning across the languages. Indeed, when non-cognate words are mispronounced, bilinguals respond like monolinguals, showing less robust recognition than when words are correctly pronounced (Ramon-Casas \& Bosch, 2010). Similarly, infants exposed to two dialects of the same language show less sensitivity to variant pronunciations than those exposed to a single dialect (Durrant, Delle Luche, Cattani, \& Floccia, 2014), perhaps mirroring infants' ability to ignore surface variation across speakers and instead attend to underlying structure (see Pardo, this volume, and Pisoni, this volume; Graf Estes \& Lew-Williams, 2015).

Accents are another type of variation that alters the phonetic form of speech. Young infants have difficulty learning and recognizing words spoken in a non-native accent, although children improve with age and through experience with a particular accent (Best, Tyler, Gooding, Orlando, \& Quann, 2009; Schmale, Cristià, \& Seidl, 2012; Schmale, Hollich, \& Seidl, 2011). It is not surprising that 
children show some difficulty processing unfamiliar accents, as adults often show similar difficulties (Cristià et al., 2012).

Despite some parallels across the lifespan, infants are sometimes sensitive to phonetic variation that adults ignore. In one study, monolinguals learned new words best from a monolingual speaker, and bilinguals learned new words best from a bilingual speaker, even though the differences between the two speakers' pronunciations were very subtle (Fennell \& Byers-Heinlein, 2014). This suggests that children are highly tuned to their language learning environments - something that researchers must take into account as they design studies comparing infants from different language backgrounds (Byers-Heinlein, 2014a). However, there is other evidence that children gravitate away from their parents' accent towards the accent of their wider communities. Twenty-month-old children exposed to two different English accents, one from their parents at home and one in their communities, are best at identifying words pronounced in the accent of their communities (Floccia, Luche, Durrant, Butler, \& Goslin, 2012). While these studies provide somewhat conflicting patterns of results, they underscore how sensitive children's comprehension can be to subtle sound changes.

Some types of imperfect speech can actually boost children's comprehension. Much of everyday speech contains disfluencies such as "um", "ah", and silent pauses. Interestingly, young children can exploit this information to their advantage, by capitalizing on the fact that disfluencies are particularly likely before unfamiliar and infrequent words. In one study, when 2-year-olds heard a target noun preceded by a disfluency, e.g., "Look at thee, uh, ...", they expected that the next word referred to an unfamiliar object, rather than to a familiar object (Kidd, White, \& Aslin, 2011). Adults share similar expectations that disfluencies signal new information (Arnold, Fagnano, \& Tanenhaus, 2003). 


\section{Conclusions}

While we often take particular joy in children's first words, children's early language comprehension constitutes an equally important, albeit somewhat hidden, side of language development. Early language comprehension sets the stage for successful development in many other areas, including language production (Fenson et al., 2007), and school-aged cognitive and language skills (Marchman \& Fernald, 2008). This chapter has followed children's path to language comprehension: from orienting to their native language(s), to picking out the sound patterns of words and learning their meanings, to understanding speech in real-time. Children show remarkable flexibility in adapting to their language-learning environments, whether they are monolingual or multilingual. 


\section{References}

Arias-Trejo, N., \& Plunkett, K. (2009). Lexical-semantic priming effects during infancy. Philosophical Transactions of the Royal Society B: Biological Sciences, 364(1536), 3633-3647. doi:10.1098/rstb.2009.0146

Arnold, J. E., Fagnano, M., \& Tanenhaus, M. K. (2003). Disfluencies Signal Theee, Um, New Information. Journal of Psycholinguistic Research, 32(1), 25-36. doi:10.1023/A:1021980931292

Aslin, R. N., Saffran, J. R., \& Newport, E. L. (1998). Computation of conditional probability statistics by 8-month-old infants. Psychological Science, 9(4), 321-324. doi:10.1111/1467-9280.00063

Bailey, T., \& Plunkett, K. (2002). Phonological specificity in early words. Cognitive Development, 17(2), 1265-1282.

Baldwin, D. A., \& Moses, L. (2001). Links between social understanding and early word learning: Challenges to current accounts. Social Development, 10(3), 309-329. doi:10.1111/14679507.00168

Baldwin, D. A., Markman, E. M., Bill, B., Desjardins, R. N., Irwin, J. M., \& Tidball, G. (1996). Infants' reliance on a social criterion for establishing word-object relations. Child Development, 67(6), 3135-3153. doi:10.2307/1131771

Bergelson, E., \& Swingley, D. (2012). At 6-9 months, human infants know the meanings of many common nouns. Proceedings of the National Academy of Sciences, 109(9), 3253-3258. doi:10.1073/pnas.1113380109

Bergelson, E., \& Swingley, D. (2013). The acquisition of abstract words by young infants. Cognition, 127(3), 391-397. doi:10.1016/j.cognition.2013.02.011

Best, C. T., Tyler, M. D., Gooding, T. N., Orlando, C. B., \& Quann, C. A. (2009). Development of phonological constancy: Toddlers' perception of native-and Jamaican-accented words. Psychological Science, 20(5), 539-542.

Bialystok, E., Luk, G., Peets, K. F., \& Yang, S. (2010). Receptive vocabulary differences in monolingual and bilingual children. Bilingualism: Language and Cognition, 13(04), 525-531. doi:10.1017/S1366728909990423

Bloom, P., \& Markson, L. (1998). Capacities underlying word learning. Trends in Cognitive Sciences, 2(2), 67-73. doi:10.1016/S1364-6613(98)01121-8

Bortfeld, H., Morgan, J. L., Golinkoff, R. M., \& Rathbun, K. (2005). Mommy and me: Familiar names help launch babies into speech segmentation. Psychological Science, 16(4), 298-304. doi:10.1111/j.0956-7976.2005.01531.x

Bosch, L., \& Sebastián-Gallés, N. (2001). Evidence of early language discrimination abilities in infants from bilingual environments. Infancy, 2(1), 29-49. doi:10.1207/S15327078IN0201_3

Bosch, L., \& Sebastián-Gallés, N. (2003). Simultaneous bilingualism and the perception of a languagespecific vowel contrast in the first year of life. Language and Speech, 46(2-3), 217-243. doi:10.1177/00238309030460020801

Brent, M. R., \& Cartwright, T. A. (1996). Distributional regularity and phonotactic constraints are useful for segmentation. Cognition, 61(1), 93-125. doi: 10.1016/S0010-0277(96)00719-6

Brent, M. R., \& Siskind, J. M. (2001). The role of exposure to isolated words in early vocabulary development. Cognition, 81(2), B33-B44. doi:10.1016/S0010-0277(01)00122-6

Burns, T. C., Yoshida, K. A., Hill, K., \& Werker, J. F. (2007). The development of phonetic representation in bilingual and monolingual infants. Applied Psycholinguistics, 28(03), 455-474. doi:10.1017/S0142716407070257 
Byers-Heinlein, K. (2014a). Bilingual advantages, bilingual delays: Sometimes an illusion. [Peer commentary on "Moving toward a neuroplasticity view of bilingualism, executive control and aging" by S. Baum \& D. Titone]. Applied Psycholinguistics, 35(05), 902-905. http://doi.org/10.1017/S0142716414000204

Byers-Heinlein, K. (2014b). Languages as categories: Reframing the "one language or two" question in early bilingual development. Language Learning. doi:10.1111/lang.12055

Byers-Heinlein, K., \& Fennell, C. T. (2014). Perceptual narrowing in the context of increased variation: Insights from bilingual infants. Developmental Psychobiology, 56(2), 274-291. doi:10.1002/dev.21167

Byers-Heinlein, K., \& Lew-Williams, C. (2014). Bilingualism in the early years: What the science says. LEARNing Landscapes, 1-18.

Byers-Heinlein, K., \& Werker, J. F. (2009). Monolingual, bilingual, trilingual: Infants' language experience influences the development of a word - learning heuristic. Developmental Science, 12(5), 815-823. doi:10.1111/j.1467-7687.2009.00902.x

Byers-Heinlein, K., \& Werker, J. F. (2013). Lexicon structure and the disambiguation of novel words: Evidence from bilingual infants. Cognition, 128(3), 407-416. doi:10.1016/j.cognition.2013.05.010

Byers-Heinlein, K., Burns, T. C., \& Werker, J. F. (2010). The roots of bilingualism in newborns. Psychological Science, 21(3), 343-348. doi:10.1177/0956797609360758

Byers-Heinlein, K., Fennell, C. T., \& Werker, J. F. (2012). The development of associative word learning in monolingual and bilingual infants. Bilingualism: Language and Cognition, 16(1), 198-205. doi:10.1017/S1366728912000417

Carey, S., \& Bartlett, E. (1978). Acquiring a single new word. Proceedings of the Stanford Child Language Conference, 15, 17-29.

Cristià, A., Seidl, A. H., Vaughn, C., Schmale, R., Bradlow, A., \& Floccia, C. (2012). Linguistic processing of accented speech across the lifespan. Frontiers in Psychology, 3. doi:10.3389/fpsyg.2012.00479/abstract

De Houwer, A., Bornstein, M. H., \& De Coster, S. (2006). Early understanding of two words for the same thing: A CDI study of lexical comprehension in infant bilinguals. International Journal of Bilingualism, 10(3), 331-347. doi:10.1177/13670069060100030401

De Houwer, A., Bornstein, M. H., \& Putnick, D. L. (2013). A bilingual-monolingual comparison of young children's vocabulary size: Evidence from comprehension and production. Applied Psycholinguistics, 1-23. doi:10.1017/S0142716412000744

Dietrich, C., Swingley, D., \& Werker, J. F. (2007). Native language governs interpretation of salient speech sound differences at 18 months. Proceedings of the National Academy of Sciences, 104(41), 16027-16031. doi:10.1073/pnas.0705270104

Dunn, L. M., \& Dunn, L. M. (2007). PPVT-4: Peabody Picture Vocabulary Test. Minneapolis, MN: Pearson Assessments.

Durrant, S., Delle Luche, C., Cattani, A., \& Floccia, C. (2014). Monodialectal and multidialectal infants' representation of familiar words. Journal of Child Language. doi:10.1017/S0305000914000063

Fennell, C. T. (2011). Object familiarity enhances infants' use of phonetic detail in novel words. Infancy, 17(3), 339-353. doi:10.1111/j.1532-7078.2011.00080.x

Fennell, C. T., \& Byers-Heinlein, K. (2014). You sound like Mommy: Bilingual and monolingual infants learn words best from speakers typical of their language environments. International Journal of Behavioral Development, 38(4), 309-316. doi:10.1177/0165025414530631

Fenson, L., Marchman, V. A., Thal, D. J., Dale, P. S., Steven Reznick, J., \& Bates, E. (2007). MacArthur- 
Bates Communicative Development Inventories (2nd ed.). Baltimore, MD: Brookes.

Ferguson, B., Graf, E., \& Waxman, S. R. (2014). Infants use known verbs to learn novel nouns:

Evidence from 15- and 19-month-olds. Cognition, 131(1), 139-146.

doi:10.1016/j.cognition.2013.12.014

Fernald, A., \& Hurtado, N. (2006). Names in frames: Infants interpret words in sentence frames faster than words in isolation. Developmental Science, 9(3), F33-F40. doi:10.1111/j.1467-

7687.2006.00482.x

Fernald, A., \& Marchman, V. A. (2012). Individual differences in lexical processing at 18 months predict vocabulary growth in typically developing and late-talking toddlers. Child Development, 83(1), 203-222. doi:10.1111/j.1467-8624.2011.01692.x

Fernald, A., \& Simon, T. (1984). Expanded intonation contours in mothers' speech to newborns. Developmental Psychology, 20(1), 104-113. doi:10.1037/0012-1649.20.1.104

Fernald, A., Pinto, J., Swingley, D., Weinberg, A., \& McRoberts, G. W. (1998). Rapid gains in speed of verbal processing by infants in the 2nd year. Psychological Science, 9(3), 228-231.

doi:10.1111/1467-9280.00044

Fernald, A., Thorpe, K., \& Marchman, V. A. (2010). Blue car, red car: Developing efficiency in online interpretation of adjective-noun phrases. Cognitive Psychology, 60(3), 190-217.

doi:10.1016/j.cogpsych.2009.12.002

Floccia, C., Luche, C. D., Durrant, S., Butler, J., \& Goslin, J. (2012). Parent or community: Where do $20-$ month-olds exposed to two accents acquire their representation of words? Cognition, 124(1), 95100. doi:10.1016/j.cognition.2012.03.011

Frank, M. C., Goodman, N. D., \& Tenenbaum, J. B. (2009). Using speakers' referential intentions to model early cross-situational word learning. Psychological Science, 20(5), 578-585.

Friedrich, M., \& Friederici, A. D. (2005). Phonotactic knowledge and lexical-semantic processing in one-year-olds: Brain responses to words and nonsense words in picture contexts. Journal of Cognitive Neuroscience, 17(11), 1785-1802. doi:10.1162/089892905774589172

Gentner, D. (1982). Why nouns are learned before verbs: Linguistic relativity versus natural partitioning. In S. Kuczaj, (Vol. 2, pp. 301-334). Hillsdale, NJ: Language Development.

Gibson, T. A., Oller, D. K., Jarmulowicz, L., \& Ethington, C. A. (2011). The receptive-expressive gap in the vocabulary of young second-language learners: Robustness and possible mechanisms. Bilingualism: Language and Cognition, 1-15. doi:10.1017/S1366728910000490

Gogate, L. J., \& Bahrick, L. E. (2001). Intersensory redundancy and 7-month-old infants' memory for arbitrary syllable-object relations. Infancy, 2(2), 219-231. doi:10.1207/S15327078IN0202_7

Graf Estes, K., \& Bowen, S. (2013). Learning about sounds contributes to learning about words: Effects of prosody and phonotactics on infant word learning. Journal of Experimental Child Psychology, 114(3), 405-417. doi:10.1016/j.jecp.2012.10.002

Graf Estes, K., Evans, J. L., Alibali, M. W., \& Saffran, J. R. (2007). Can infants map meaning to newly segmented words? Statistical segmentation and word learning. Psychological Science, 13(3), 254260. doi:10.1111/j.1467-9280.2007.01885.x

Graf Estes, K., \& Lew-Williams, C. (2015). Listening through voices: Infant statistical word segmentation across multiple speakers. Developmental Psychology, 51, 1517-1528. doi: $10.1037 / a 0039725$

Grieco-Calub, T. M., Saffran, J. R., \& Litovsky, R. Y. (2009). Spoken word recognition in toddlers who use cochlear implants. Journal of Speech, Language and Hearing Research, 52(6), 1390-1400.

Halberda, J. (2003). The development of a word-learning strategy. Cognition, 87(1), B23-B34. 
doi:10.1016/S0010-0277(02)00186-5

Hart, B., \& Risley, T. R. (1995). Meaningful differences in the everyday experience of young American children. Baltimore: Brookes.

Hollich, G., Golinkoff, R. M., \& Hirsh-Pasek, K. (2007). Young children associate novel words with complex objects rather than salient parts. Developmental Psychology, 43(5), 1051-1061. doi: 10.1037/0012-1649.43.5.1051.

Hollich, G., Hirsh-Pasek, K., \& Golinkoff, R. M. (2000). The emergentist coalition model. Monographs of the Society for Research in Child Development, 65(3), 17-29. doi:10.1111/1540-5834.00092

Von Holzen, K., \& Mani, N. (2012). Language nonselective lexical access in bilingual toddlers. Journal of Experimental Child Psychology, 113(4). doi:10.1016/j.jecp.2012.08.001

Horst, J., \& Samuelson, L. K. (2008). Fast mapping but poor retention by 24-month-old infants. Infancy, 13(2), 128-157. doi:10.1080/15250000701795598

Houston, D. M., \& Jusczyk, P. W. (2000). The role of talker-specific information in word segmentation by infants. Journal of Experimental Psychology: Human Perception and Performance, 36, 15701582. doi:10.1037/0096-1523.26.5.1570

Houston, D. M., \& Jusczyk, P. W. (2003). Infants' long-term memory for the sound patterns of words and voices. Journal of Experimental Psychology: Human Perception and Performance, 29(6), 11431154. doi:10.1037/0096-1523.29.6.1143

Houston-Price, C., Caloghiris, Z., \& Raviglione, E. (2010). Language experience shapes the development of the mutual exclusivity bias. Infancy, 15(2), 125-150. doi:10.1111/j.15327078.2009.00009.x

Hurtado, N., Grueter, T., Marchman, V. A., \& Fernald, A. (2014). Relative language exposure, processing efficiency and vocabulary in Spanish-English bilingual toddlers. Bilingualism: Language and Cognition, 17(01), 189-202. doi:10.1017/S136672891300014X

Hurtado, N., Marchman, V. A., \& Fernald, A. (2007). Spoken word recognition by Latino children learning Spanish as their first language. Journal of Child Language, 34(02), 227. doi:10.1017/S0305000906007896

Huttenlocher, J., Haight, W., Bryk, A., Seltzer, M., \& Lyons, T. (1991). Early vocabulary growth: Relation to language input and gender. Developmental Psychology, 27(2), 236-248. doi:doi:10.1037/00121649.27.2.236

Johnson, E. K., \& Jusczyk, P. W. (2001). Word segmentation by 8-month-olds: When speech cues count more than statistics. Journal of Memory and Language, 44(4), 548-567. doi:10.1006/jmla.2000.2755

Johnson, E. K., \& Seidl, A. H. (2009). At 11 months, prosody still outranks statistics. Developmental Science, 12(1), 131-141. doi:10.1111/j.1467-7687.2008.00740.x

Johnson, E. K., \& Tyler, M. D. (2010). Testing the limits of statistical learning for word segmentation. Developmental Science, 13(2), 339-345. doi:10.1111/j.1467-7687.2009.00886.x

Johnson, E. K., Seidl, A. H., \& Tyler, M. D. (2014). The edge factor in early word segmentation: Utterance-level prosody enables word form extraction by 6-month-olds. PLOS ONE, 9(1), e83546. doi:10.1371/journal.pone.0083546.s001

Jusczyk, P. W., \& Aslin, R. N. (1995). Infants' detection of the sound patterns of words in fluent speech. Cognitive Psychology, 29(1), 1-23. doi:10.1006/cogp.1995.1010

Jusczyk, P. W., Houston, D. M., \& Newsome, M. (1999). The beginnings of word segmentation in English-learning infants. Cognitive Psychology, 39, 159-207. doi:10.1006/cogp.1999.0716 Kidd, C., White, K. S., \& Aslin, R. N. (2011). Toddlers use speech disfluencies to predict speakers' 
referential intentions. Developmental Science, 14(4), 925-934. doi:10.1111/j.1467-

7687.2011.01049.x

Krentz, U. C., \& Corina, D. P. (2008). Preference for language in early infancy: The human language bias is not speech specific. Developmental Science, 11(1), 1-9. doi:10.1111/j.1467-

7687.2007.00652.x

Kuhl, P. K., Conboy, B. T., Coffey-Corina, S., Padden, D., Rivera-Gaxiola, M., \& Nelson, T. (2007). Phonetic learning as a pathway to language: New data and native language magnet theory expanded (NLM-e). Philosophical Transactions of the Royal Society B: Biological Sciences, 363(1493), 979-1000. doi:10.1098/rstb.2007.2154

Lew-Williams, C., \& Fernald, A. (2007). Young children learning Spanish make rapid use of grammatical gender in spoken word recognition. Psychological Science, 18(3), 193-198. doi:10.1111/j.14679280.2007.01871.x

Lew-Williams, C., \& Saffran, J. R. (2012). All words are not created equal: Expectations about word length guide infant statistical learning. Cognition, 122(2), 241-246.

doi:10.1016/j.cognition.2011.10.007

Lew-Williams, C., Pelucchi, B., \& Saffran, J. R. (2011). Isolated words enhance statistical language learning in infancy. Developmental Science, 14(6), 1323-1329.

Mackenzie, H., Curtin, S., \& Graham, S. A. (2012a). 12-month-olds' phonotactic knowledge guides their word-object mappings. Child Development, 83(4), 1129-1136. doi:10.1111/j.14678624.2012.01764.x

Mackenzie, H., Curtin, S., \& Graham, S. A. (2012b). Class matters: 12-month-olds' word-object associations privilege content over function words. Developmental Science, 15(6), 753-761. doi:10.1111/j.1467-7687.2012.01166.x

Mani, N., Durrant, S., \& Floccia, C. (2012). Activation of phonological and semantic codes in toddlers. Journal of Memory and Language, 66(4), 612-622. doi:10.1016/j.jml.2012.03.003

Marchman, V. A., \& Fernald, A. (2008). Speed of word recognition and vocabulary knowledge in infancy predict cognitive and language outcomes in later childhood. Developmental Science, 11(3), F9-F16. doi:10.1111/j.1467-7687.2008.00671.x

Marchman, V. A., Fernald, A., \& Hurtado, N. (2010). How vocabulary size in two languages relates to efficiency in spoken word recognition by young Spanish-English bilinguals. Journal of Child Language, 37(4), 817-840. doi:10.1017/S0305000909990055

Markman, E. M. (1991). The whole-object, taxonomic, and mutual exclusivity assumptions as initial constraints on word meanings. In Perspectives on Language and Thought: Interrelations in Development. Cambridge Univ Press.

Markman, E. M., \& Wachtel, G. F. (1988). Children's use of mutual exclusivity to constrain the meanings of words. Cognitive Psychology, 20(2), 121-157. doi:10.1016/0010-0285(88)90017-5

Markman, E. M., Wasow, J. L., \& Hansen, M. B. (2003). Use of the mutual exclusivity assumption by young word learners. Cognitive Psychology, 47(3), 241-275. doi:10.1016/S0010-0285(03)00034-3

Martin, A., Onishi, K. H., \& Vouloumanos, A. (2012). Understanding the abstract role of speech in communication at 12 months. Cognition, 123(1), 50-60. doi:10.1016/j.cognition.2011.12.003

Matatyaho-Bullaro, D. J., Gogate, L., Mason, Z., Cadavid, S., \& Abdel-Mottaleb, M. (2014). Type of object motion facilitates word mapping by preverbal infants. Journal of Experimental Child Psychology, 118(C), 27-40. doi:10.1016/j.jecp.2013.09.010

Maye, J., Werker, J. F., \& Gerken, L. (2002). Infant sensitivity to distributional information can affect phonetic discrimination. Cognition, 82(3), B101-B111. doi:10.1016/S0010-0277(01)00157-3 
Mayor, J., \& Plunkett, K. (2011). A statistical estimate of infant and toddler vocabulary size from CDI analysis. Developmental Science, 14(4), 769-785. doi:10.2307/25057972 ?ref=no-xroute:58a0ca288783055a71a92e8d3b06ac76

McCabe, A., Tamis-LeMonda, C., Bornstein, M., Golinkoff, R. M., Hirsh-Pasek, K., Hoff, E., Kuchiro, Y., Melzi, G., Mendelson, A., Paez, M., Song, L., \& Wishard, A. (2013). Multilingual children: Beyond myths towards best practices. Social Policy Report for the Society for Research in Child Development, 27(4).

Mehler, J., Jusczyk, P. W., Lambertz, G., Halsted, N., Bertoncini, J., \& Amiel-Tison, C. (1988). A precursor of language acquisition in young infants. Cognition, 29(2), 143-178. doi:10.1016/00100277(88)90035-2

Mersad, K., \& Nazzi, T. (2012). When mommy comes to the rescue of statistics: Infants combine topdown and bottom-up cues to segment speech. Language Learning and Development, 8(3), 303315. doi:10.1080/15475441.2011.609106

Mills, D. L., Plunkett, K., Prat, C., \& Schafer, G. (2005). Watching the infant brain learn words: Effects of vocabulary size and experience. Cognitive Development, 20(1), 19-31. doi:10.1016/j.cogdev.2004.07.001

Molnar, M., Gervain, J., \& Carreiras, M. (2014). Within-rhythm class native language discrimination abilities of Basque-Spanish monolingual and bilingual infants at 3.5 months of age. Infancy, 19(3), 326-337. doi:10.1111/infa.12041

Moon, C., Cooper, R., \& Fifer, W. (1993). Two-day-olds prefer their native language. Infant Behavior and Development, 16(4), 495-500. doi:10.1016/0163-6383(93)80007-U

Naigles, L. R. (1990). Children use syntax to learn verb meanings. Journal of Child Language, 17(02), 357-374. doi:10.1017/S0305000900013817

Nazzi, T., Bertoncini, J., \& Mehler, J. (1998). Language discrimination by newborns: Toward an understanding of the role of rhythm. Journal of Experimental Psychology: Human Perception and Performance, 24(3), 756-766. doi:10.1037/0096-1523.24.3.756

Nazzi, T., Jusczyk, P. W., \& Johnson, E. K. (2000). Language discrimination by English-learning 5-montholds: Effects of rhythm and familiarity. Journal of Memory and Language, 43(1), 1-19. doi:10.1006/jmla.2000.2698

Pearson, B. Z., Fernández, S. C., \& Oller, D. K. (1995). Cross-language synonyms in the lexicons of bilingual infants: One language or two? Journal of Child Language, 22(2), 345-368. doi:10.1017/S030500090000982X

Pelucchi, B., Hay, J. F., \& Saffran, J. R. (2009). Statistical learning in a natural language by 8-month-old infants. Child Development, 80(3), 674-685. doi:10.1111/j.1467-8624.2009.01290.x

Peña, E. D., Gillam, R. B., Bedore, L. M., \& Bohman, T. M. (2011). Risk for poor performance on a language screening measure for bilingual preschoolers and kindergarteners. American Journal of Speech-Language Pathology, 20(4), 302. doi:10.1044/1058-0360(2011/10-0020)

Petitto, L. A., Katerelos, M., Levy, B. G., Gauna, K., Tetreault, K., \& Ferraro, V. (2001). Bilingual signed and spoken language acquisition from birth: Implications for the mechanisms underlying early bilingual language acquisition. Journal of Child Language, 28(2), 453-496.

Polka, L., \& Sundara, M. (2003). Word segmentation in monolingual and bilingual infant learners of English and French. Proceedings of the 15th International Congress of Phonetic Sciences, 10211024.

Polka, L., \& Sundara, M. (2012). Word segmentation in monolingual infants acquiring Canadian English and Canadian French: Native language, cross-dialect, and cross-language comparisons. Infancy, 
17(2), 198-232. doi:10.1111/j.1532-7078.2011.00075.x

Poulin-Dubois, D., Bialystok, E., Blaye, A., Polonia, A., \& Yott, J. (2012). Lexical access and vocabulary development in very young bilinguals. International Journal of Bilingualism, 17(1), 1-15. doi:10.1177/1367006911431198

Ramon-Casas, M., \& Bosch, L. (2010). Are non-cognate words phonologically better specified than cognates in the early lexicon of bilingual children? In M. Ortega-Llebaria, Proceedings of the 4th Conference on Laboratory Approaches to Spanish Phonology (pp. 31-36). Sommerville, MA: Cascadilla.

Ramon-Casas, M., Swingley, D., Sebastián-Gallés, N., \& Bosch, L. (2009). Vowel categorization during word recognition in bilingual toddlers. Cognitive Psychology, 59(1), 96-121. doi:10.1016/j.cogpsych.2009.02.002

Rice, M. L., Warren, S. F., \& Betz, S. K. (2005). Language symptoms of developmental language disorders: An overview of autism, Down syndrome, fragile $X$, specific language impairment, and Williams syndrome. Applied Psycholinguistics, 26(01), 7-27. doi:10.1017/\$0142716405050034

Romberg, A. R., \& Saffran, J. R. (2010). Statistical learning and language acquisition. Wiley Interdisciplinary Reviews: Cognitive Science, 1(6), 906-914. doi:10.1002/wcs.78

Saffran, J. R., Aslin, R. N., \& Newport, E. L. (1996). Statistical learning by 8-month-old infants. Science, 274(5294), 1926-1928. doi:10.1126/science.274.5294.1926

Schmale, R., Cristià, A., \& Seidl, A. H. (2012). Toddlers recognize words in an unfamiliar accent after brief exposure. Developmental Science, 15(6), 732-738. doi:10.1111/j.1467-7687.2012.01175.x

Schmale, R., Hollich, G., \& Seidl, A. H. (2011). Contending with foreign accent in early word learning. Journal of Child Language, 1-13. doi:10.1017/\$0305000910000619

Sebastián-Gallés, N., \& Bosch, L. (2009). Developmental shift in the discrimination of vowel contrasts in bilingual infants: Is the distributional account all there is to it? Developmental Science, 12(6), 874-887. doi:10.1111/j.1467-7687.2009.00829.x

Sebastián-Gallés, N., Albareda-Castellot, B., Weikum, W. M., \& Werker, J. F. (2012). A bilingual advantage in visual language discrimination in infancy. Psychological Science, 23(9), 994-999. doi:10.1177/0956797612436817

Seidl, A. H., Tincoff, R., Baker, C., \& Cristià, A. (2014). Why the body comes first: Effects of experimenter touch on infants' word finding. Developmental Science. Advance online publication. doi:10.1111/desc.12182

Shukla, M., Nespor, M., \& Mehler, J. (2007). An interaction between prosody and statistics in the segmentation of fluent speech. Cognitive Psychology, 54(1), 1-32. doi:10.1016/j.cogpsych.2006.04.002

Shukla, M., White, K. S., \& Aslin, R. N. (2011). Prosody guides the rapid mapping of auditory word forms onto visual objects in 6-mo-old infants. Proceedings of the National Academy of Sciences, 108(15), 6038-6043. doi:10.1073/pnas.1017617108

Singh, L. (2013). One world, two languages: Cross-language semantic priming in bilingual toddlers. Child Development. doi:10.1111/cdev.12133

Smith, L. B., \& Yu, C. (2008). Infants rapidly learn word-referent mappings via cross-situational statistics. Cognition, 106(3), 1558-1568. doi:10.1016/j.cognition.2007.06.010

Smith, L. B., Jones, S., Landau, B., Gershkoff-Stowe, L., \& Samuelson, L. K. (2002). Object name learning provides on-the-job training for attention. Psychological Science, 13(1), 13-19. doi:10.1111/1467-9280.00403

Stager, C. L., \& Werker, J. F. (1997). Infants listen for more phonetic detail in speech perception than 
in word-learning tasks. Nature, 388(6640), 381-382. doi:10.1038/41102

Sundara, M., \& Scutellaro, A. (2010). Rhythmic distance between languages affects the development of speech perception in bilingual infants. Journal of Phonetics, 39(4), 505-513. doi:10.1016/j.wocn.2010.08.006

Sundara, M., Polka, L., \& Molnar, M. (2008). Development of coronal stop perception: Bilingual infants keep pace with their monolingual peers. Cognition, 108(1), 232-242. doi:10.1016/j.cognition.2007.12.013

Swingley, D. (2005). 11-month-olds' knowledge of how familiar words sound. Developmental Science, 8(5), 432-443. doi:10.1111/j.1467-7687.2005.00432.x

Swingley, D. (2010). Fast mapping and slow mapping in children's word learning. Language Learning and Development, 6(3), 179-183. doi:10.1080/15475441.2010.484412

Swingley, D., Pinto, J., \& Fernald, A. (1999). Continuous processing in word recognition at 24 months. Cognition, 71(2), 73-108. doi:10.1016/S0010-0277(99)00021-9

Thiessen, E. D., \& Pavlik, P. I. (2013). iMinerva: A mathematical model of distributional statistical learning. Cognitive Science: a Multidisciplinary Journal, 37(2), 310-343.

Thiessen, E. D., \& Saffran, J. R. (2003). When cues collide: Use of stress and statistical cues to word boundaries by 7- to 9-month-old infants. Developmental Psychology, 39(4), 706-716. doi:10.1037/0012-1649.39.4.706

Thordardottir, E. (2011). The relationship between bilingual exposure and vocabulary development. International Journal of Bilingualism, 1-21. doi:10.1177/1367006911403202

Tincoff, R., \& Jusczyk, P. W. (2011). Six-month-olds comprehend words that refer to parts of the body. Infancy 17(4), 432-444. doi:10.1111/j.1532-7078.2011.00084.x

Umbel, V., Pearson, B. Z., Fernández, M., \& Oller, D. K. (1992). Measuring bilingual children's receptive vocabularies. Child Development, 63(4), 1012-1020. doi:10.2307/1131250

Venker, C. E., Eernisse, E. R., Saffran, J. R., \& Weismer, S. E. (2013). Individual differences in the realtime comprehension of children with ASD. Autism Research, 6(5), 417-432. doi:10.1002/aur.1304

Vihman, M. M., Thierry, G., Lum, J., Keren-Portnoy, T., \& Martin, P. (2007). Onset of word form recognition in English, Welsh, and English-Welsh bilingual infants. Applied Psycholinguistics, 28(3), 475-493. doi:10.1017/S0142716407070269

Vouloumanos, A., \& Werker, J. F. (2007). Listening to language at birth: Evidence for a bias for speech in neonates. Developmental Science, 10(2), 159-164. doi:10.1111/j.1467-7687.2007.00549.x

Vouloumanos, A., \& Werker, J. F. (2009). Infants' learning of novel words in a stochastic environment. Developmental Psychology, 45(6), 1611-1617. doi:10.1037/a0016134

Waxman, S. R., \& Gelman, S. A. (2009). Early word-learning entails reference, not merely associations. Trends in Cognitive Sciences, 13(6), 258-263. doi:10.1016/j.tics.2009.03.006

Waxman, S. R., Lidz, J. L., Braun, I. E., \& Lavin, T. (2009). Twenty four-month-old infants' interpretations of novel verbs and nouns in dynamic scenes. Cognitive Psychology, 59(1), 67-95. doi:10.1016/j.cogpsych.2009.02.001

Weikum, W. M., Vouloumanos, A., Navarra, J., Soto-Faraco, S., Sebastián-Gallés, N., \& Werker, J. F. (2007). Visual language discrimination in infancy. Science, 316(5828), 1159. doi:10.1126/science.1137686

Weisleder, A., \& Fernald, A. (2013). Talking to children matters: Early language experience strengthens processing and builds vocabulary. Psychological Science, 1-22. doi:10.1177/0956797613488145

Werker, J. F., \& Byers-Heinlein, K. (2008). Bilingualism in infancy: First steps in perception and 
comprehension. Trends in Cognitive Sciences, 12(4), 144-151. doi:10.1016/j.tics.2008.01.008

Werker, J. F., \& Tees, R. C. (1984). Cross-language speech perception: Evidence for perceptual reorganization during the first year of life. Infant Behavior and Development, 7(1), 49-63. doi:10.1016/S0163-6383(84)80022-3

Werker, J. F., Cohen, L., Lloyd, V., Casasola, M., \& Stager, C. L. (1998). Acquisition of word-object associations by 14-month-old infants. Developmental Psychology, 34(6), 1289-1309. doi:10.1037/0012-1649.34.6.1289

White, K. S., \& Morgan, J. L. (2008). Sub-segmental detail in early lexical representations. Journal of Memory and Language, 59(1), 114-132. doi:10.1016/j.jml.2008.03.001

Yeung, H. H., \& Werker, J. F. (2009). Learning words' sounds before learning how words sound: 9Month-olds use distinct objects as cues to categorize speech information. Cognition, 1-10. doi:10.1016/j.cognition.2009.08.010

Yeung, H. H., Chen, L. M., \& Werker, J. F. (2013). Referential labeling can facilitate phonetic learning in infancy. Child Development. doi:10.1111/cdev.12185

Yow, W. Q., \& Markman, E. M. (2011). Young bilingual children's heightened sensitivity to referential cues. Journal of Cognition and Development, 12(1), 12-31. doi:10.1080/15248372.2011.539524

Yu, C., \& Smith, L. B. (2012). Embodied attention and word learning by toddlers. Cognition, 125(2), 244-262. doi:10.1016/j.cognition.2012.06.016

Zangl, R., Klarman, L., Thal, D. J., Fernald, A., \& Bates, E. (2005). Dynamics of word comprehension in infancy: Developments in timing, accuracy, and resistance to acoustic degradation. Journal of Cognition and Development, 6(2), 179-208. doi:10.1207/s15327647jcd0602_2 
